\title{
A Statistical Approach to Life Quality Analysis
}

\author{
Lyudmila P. Bakumenko
}

Tatyana V. Sarycheva

Tatiana A. Ignasheva

\author{
Mari State University, Yoshkar-Ola, Russia \\ Email: Ipbakum@mail.ru \\ Vladimir S. Mkhitaryan \\ National Research University "Higher School of Economics", Moscow, Russia \\ Email: vmkhitarian@hse.ru \\ Petr A. Korotkov \\ Volga State University of Technology, Yoshkar-Ola, Russia \\ Email:korotp@bk.ru
}

Doi:10.5901/mjss.2015.v6n3s7p79

\section{Abstract}

The article deals with the approaches to the study of population life quality in countries around the world. We considered the formation of the main Human Development Index, calculated annually by the United Nations, its composition and method of calculating the indicators, changes in the structure and calculation of the indicators of the HDI. According to the data of the 2014 United Nations Report, all countries of the world were divided into four groups: the countries with very high human development level, the countries with high human development level, the countries with medium human development level and the countries with low human development level. In the paper the complex analysis of human development is conducted for the group with very high level of development. In the study we suggested the method of selection of integrated, generalizing indicators using the method of dimension reduction - the method of principal components. By the method of principal components the generalizing integrated indicators, which allowed assessing living conditions of the population at the most generalized level, were identified. The principal factors were selected taking into account the total accumulated dispersion, Kaiser criterion and the scree plot. In the result of the recalculations with the axes rotation by the method of Varimax of initials, three principal components were obtained. The model of dependance of the Human Development Index (HDI) $-y$ on the selected principal factors $\mathrm{f1}, \mathrm{f} 2$ and $\mathrm{f3}$ was built. The countries, included to the first group with very high human development level were classified using cluster analysis. The classification was carried out by the selected generalizing factors. In the result of hierarchical procedures for combining, we identified four groups of countries - four clusters, which confirm the differences in the conditions of human development in the group of countries with very high human development level.

Keywords: population life quality, human development level, method of principal components, generalizing indicators, regression model, cluster analysis

\section{Introduction}

Quality of life is recognized by the international community as one of the main categories, which characterize the development of countries and peoples in the XXI century. The XXI century is often called the century of the quality of life. It is the indicator of the quality of life, by which UNESCO annually makes a ranking of countries. The quality of life became a characteristic of high labour performance and a well-developed economy, a source of the national wealth and a condition for a decent life.

The concept of improving the quality of life, oriented at harmonious combination of all spheres of the life of society and individuals, becomes the new symbol of progress. Having approved the main document "Agenda for the XXI Century", the 1992 conference of world leaders in Rio-de-Janeiro determined the steady improvement of the quality of life as the shared purpose of all mankind. 
Historical experience shows that a focus on quality gave momentum to the recovery from crisis for many countries. Issues of the quality of life are considered in the innovative works of prominent foreign theorists and practicians in the sphere of quality, such as "the Gurus of Quality Management" - E. Deming, J. Juran, Ph. Crosby, K. Ishikawa, A. Feigenbaum, G. Taguchi, T.Seyfi and others (Ishikawa, 1998). By means of the state policy, aimed at quality, post-war Japan and Germany overcame major crises. Crisis situations, encountered in the late 80's - early 90's of the XX century, made the whole countries - Sweden, USA and England - appeal to quality as the only tool that can help the national economy to resist the onslaught of competitors (Deming, 1986).

World experience in dealing with crises reveals a common feature in the actions for rescuing the national economy: almost always and everywhere, where success was achieved, there was the focus on the quality of life. And almost always and everywhere the reformers took into account the national traditions and features of their national economies, national character of the people and historical experience, and supported it by the appropriate economic and legal mechanism. Such mechanism should determine the priorities in the field of socio-economic management and provide high quality of life of the general population of the country.

Due to this fact, many state and public organizations calculate the indices of the quality of life (or their equivalents) using different methodologies. These are various UN divisions ( $\mathrm{HDI} / \mathrm{IHDI})$, the World Health Organization; the World Bank; the International Society for Quality-of-Life Studies, the UNESCO Commission on Population and Quality of Life and a number of popular mass media, scientific editions, social research and consulting organizations (Bakumenko, 2012).

\section{Research Methods}

In terms of the possibility to compare various countries, the most prospective and adequate indicator of social development, which has an impact on the quality of life, is the Human Development Index (HDI), developed in the UN. Human Development Index of the UN (HDI), which is the main evaluation criterion, was developed by Pakistani economist Mahbub ul-Haq and has been used by the UN in the annual report on human development since 1990. The Human Development Report usually contains the data on the Human Development Index, which is annually calculated by the experts of the United Nations Development Programme (UNDP) in cooperation with a group of independent international experts, using in their work the statistical data of national institutes and various international organizations along with analytical developments (Bakumenko, 2011)

The index value is measured in the range from 0 to 1 . An index value of 1 corresponds to a country, in which the life expectancy is 85 years; $100 \%$ of the adult population have education; all people, reached a certain age, study in appropriate educational institutions; the gross domestic product per capita in purchasing power parity equals 40,000 USD. An index value of 0 corresponds to a country, in which the life expectancy is 25 years; $100 \%$ of the population are illiterate; nobody gets education; the gross domestic product per capita in purchasing power parity equals 100 USD.

Until 2010, The Human Development Index (HDI) measured the achievements of countries in terms of life expectancy, education and actual income. The achievements are considered for three main areas: health and longevity, measured by the life expectancy at birth; access to education, measured by the adult literacy rate and the aggregate gross education coverage; adequate standard of living, measured by the value of gross domestic product (GDP) per capita in US dollars by purchasing power parity (PPP).

Taken in equal shares, these indicators reflected the main peculiarities of the countries development: healthy and long life, education opportunities and material prosperity of the population.

These three measurements were standardized in the form of numerical values from 0 to 1 , the arithmetic mean of which represented the aggregate indicator of $\mathrm{HDI}$ in the range from 0 to 1 . Then the countries were ranked based on this indicator, and the first place in the ranking corresponded to the highest level of HDI. When defining a position in the ranking, many factors were taken into account such as civil liberties, human dignity, opportunity to participate in public life, social security, health indicators, level of cultural development of the population, state of crime, environmental protection and others. All countries were classified in four ways: by the level of human development, by income, by global aggregate indicators and by regions. The human development index is a total indicator of human development in a country (the so-called "quality of life" or "standard of living").

In 2010 the family of indicators, which measure the HDI, was extended, and the Index has undergone substantial changes.

The 20th anniversary report of the UNDP on human development (2010), entitled «The Real Wealth of Nations: Pathways to Human Development", used the official statistical data instead of subjective assessments of experts, as well as the new methods of calculating the indicators of income, health and education. Therefore this report is relatively 
objective and is amenable to verification. It allows us to take a fresh look at some of the most pressing challenges, which the humanity faces in the XXI century.

In the new method of calculating the HDI three measurements: health, education and standard of living and four indicators: the life expectancy, the average duration of studies, the expected duration of training and the gross national income per capita are used.

The gross national income per capita is used instead of gross national product that allows taking into account the income from money transfers and international development assitance. The upper income limit, introduced in order to set the weights for the index, was abolished, that allows identifying the values of the HDI, which reflect the actual income more precisely for the countries, in which the previously set limit of 40,000 USD is exceeded.

For the sphere of education, the expected duration of training of schoolchildren is used instead of gross education coverage, and the average duration of adult education is used instead of the adult literacy rate, that gives a more complete picture of education levels. As for health, life expectancy at birth remains the main indicator.

The indicators on three measurements are sorted and aggregated in order to match the range of the HDI scale from zero to one. The countries are grouped into four categories of human development, or quartiles: very high, high, medium and low levels. A country belongs: to the category with very high level of human development, if its HDI corresponds to the upper quartile; to the group with high human development level, if its HDI is in the interval from the $51^{\text {st }}$ and $75^{\text {th }}$ percentiles; to the group with medium human development level, if its HDI is between the $26^{\text {th }}$ and $50^{\text {th }}$ percentiles and to the category with low human development level, if its HDI refers to the lower quartile.

The ways of aggregating the three measurements were also reviewed. A key change was the application of the geometric mean instead of the arithmetic mean, i.e. the HDI in 2010 represents the geometric mean of three measurement indices. This method allows identfiying the differences between the measurements. It recognizes that health, education and income are important but these three measurements of well-being are difficult to compare and any changes in them should not be left out of account.

Given the use of different indicators and methods of calculation, the HDI of 2010 cannot be compared to the HDIs, published in the previous editions of the Report, since it keeps track of thy changes in the national rakinings for five-year periods, not from year to year.

In the 2010 Report, three new statistical indicators are introduced: the Inequality Adjusted Human Development Index, the Gender Inequality Index and the Multidimensional Poverty Index.

Inequality-adjusted $\mathrm{HDI}(\mathrm{IHDI})$ is a tool for measuring human development which takes into account the inequality. If the equality is ideal, the $\mathrm{HDI}$ and IHDI are equal. The value of IHDI for the average individual is lower that the aggregated $\mathrm{HDI}$; if in the society there is an inequality in the distrubution of health, education and income; the lower the $\mathrm{IHDI}$ (and the greater the difference between the IHDI and the HDI), the higher the level of inequality.

Gender Inequality Index (GII) is a new statistical index, based on the same basic indicators as the HDI and IHDI, and designed to identify the differences in the distribution of achievements between women and men.

Multidimensional Poverty Index (MPI) complements the indicators of poverty, based on income. The MPI identifies deprivations in the same measurements as the HDI (health, education, standard of living) and shows the number of people who are "multidimensionally" poor, as well as the kinds of deprivation which these people are subjected to at the household level. The MPI uses 10 indicators; a household is regarded as poor, if it faces deprivation in more than three of these areas. The MPI can be divided by regions, ethnic and other groups as well as by individual measurements. Besides, the index may be adapted more significantly taking into account the needs of the country.

Foreign experience in the development of social indices becomes adaptable for modern Russian research. However, the use of many indices in Russia is complicated due to statistical disadvantages and the absence of many indicators in the regional context.

Crisis Life Quality Index is developed in the Independent Institute of Social Policy. This index reflects the most urgent problems of the transition period, recorded in the statistical indicators of the regions. To obtain this indicator, the following specific indices are calculated: the index of the ratio of per capita income to the subsistence minimum, the index of the share of people with incomes above the subsistence level; the index of the level of employment; the index of life expectancy; the index of infant mortality. The integral index is the arithmetic mean of four indices, the latter of which combines the indices of life expectancy and infant mortality. The index is quite informative for the analysis of the problems of regional development in crisis, but it also remains relevant in the periods of economic stabilization, since it includes the indicators that have high inertia, the more especially as in many regions the economic crisis has not passed yet.

As the index of information potential it is suggested to use the Innovation Capacity Index, which, according to the most up-to-date method, is calculated based on 5 indicators: the number of staff engaged in research and development, 
$\%$ of the total number of people employed in the economy; the number of university students per 10 thousand people; the number of registered patents per 1000 people employed in the economy; the costs of technological innovations, rubles per capita; the level of internetization, \%.

Development of various generalizing integral indicators, which reflect the level and quality of life, using the methods, adopted by the worldwide community, allows conducting cross-country and regional comparisons and giving a sufficiently reliable comparative characteristic of different aspects of social progress.

In fact, there is the abundance of factors, which influence the Human Development Index. These factors cover the economic, social and political spheres of life. It is quite difficult to take into account all these factors, therefore it would be convenient to group the most important indicators and to determine their impact on human development (Bakumenko, 2011).

The Human Development Index is aimed at identiying the various factors, including the factors, defining the quality of the conditions for personality formation. If we turn to history, we can notice that the great scholars and poets mostly came from the same countries: Germany, USA, Japan, Norway, United Kingdom, etc. It was a rare occasion when prominent artists and researchers appeared in India or Africa. It turns out that in Europe and USA people are more developed. But what facilitates this? Which conditions are required for this?

According to the 2014 UN Report "Sustaining Human Progress: Reducing Vulnerabilities and Building Resilience", all countries of the world were divided into four groups: the countries with very high level of development, the countries with high level of development, the countries with medium level of development and the countries with low level of development.

\section{Data and Methods}

\subsection{The system of human development indicators}

In this study, the task was set to identify the major generalizing indicators, which characterize the quality of life in the countries, classified by the level of human developed to a group with very high level of human development.

For this purpose, a database was initially collected, which contained 23 indicators, defining the quality of living in the countries of this group. The major factors, which form the Human Development Index and the most fully reflect the standard of living, were represented by the indicators, collected by various international organizaions in different years for the comparison of life quality in the countries ${ }^{2}: x_{1}$ - satisfaction with freedom of choice (\% of satisfied); $x_{2}$ - satisfaction with society (\% of "yes"» answers); $x_{3}$ - trust in government (\% of "yes" answers); $x_{4}$ - sense of security (\% of "yes" answers); $\mathrm{x}_{5}$ - murder rate (per 100 thousand people); $\mathrm{x}_{6}$ - average duration of training (years); $\mathrm{x}_{7}$ - GNI per capita (\$); $\mathrm{x}_{8}$ - maternal mortality rate (per 100000 live birhing mothers); $x_{9}$ - adolescent fertility rate (births per 1000 women aged 15-19); $x_{10^{-}}$ seats in the national parliament (\% of women); $x_{11}$ - people with at least secondary education, women (\% of women aged 25 and above); $x_{12-}$ people with at least secondary education, men (\% of men aged 25 and above); $x_{13}-$ level of economic activity, women (\%, from 15 years old); $x_{14-}$ level of economic activity, men (\%, from 15 years old); $x_{15-}$ mortality at birth (per 1000 live births); $x_{16}$ - doctors (per 1000 people.); $x_{17}$ - people with at least secondary education (\%, older than 25 years); $x_{18}$ - electrification rate (\% of population); $x_{19}$ - presence of PC (per 100 people); $x_{20}$ - Internet access (per 100 people); $x_{21}$ - population (million); $x_{22}$ - gender ratio at birth (men to women); $x_{23}$ - overall life satisfaction (from 1 to 10).

\subsection{The method of study}

At the second stage of the study the given indicators were verified for multicollinearity using the correlation matrix, and it was decided to use the method of factor analysis - method of principal components - as the method of identifying the major factors. It gave us the opportunity to form and select generalizing integrated indicators, which would allow assessing the living conditions of the population at the most generalized level. This, in turn, involves the procedure of aggregation, "compression" of many primary characteristics to the indicators, describing the quality of living as a certain

1 In this report, the various data for various years are presented (2010-2013)

2 HDRO calculations, based on the data of UNDESA (2013), Barro and Lee (2013), the UNESCO Institute for Statistics (2013), United Nations Statistics Division (2014), World Bank (2014) and the International monetary Fund (2014), UNDESA (2013), estimates of HDRO, based on the data on educational achievements of the UNESCO Institute for Statistics (2013) and on the methodology of Barro and Lee (2013), HDRO calculations, based on the data of the World Bank (2014), the UN Statistics Division (2014). 
integrated phenomenon. The data from the initial measurements, recorded using the elementary indicators, are to make the definite "rise" and to be presented as a system of integrared social parameters, which allow conducting meaningful assessments of the state of the quality of life in general. Thus, the process of consolidation of the information is connected with the loss of informativeness and the specific content of the indicators, but at the same time, the integrated indicators have to contain a new quality of the object under study and provide the opportunity to "see" the generalized patterns and trends, which were previously hidden in a variety of individual observations (Dubrov, 2000).

Thus, in order to characterize all sides of the quality of life in the group of countires with very high level of development, in our study we have chosen quite large number of indicators, 23 initial statistical indicators of the basic level. The analysis of the selected indicators of the basic level turned out to be redundant in terms of information, poorly interpretable and was characterized by multicollinearity. The assessment of significance of factors' multicollinearity was conducted using the method of testing the hypothesis of the independence of variables ${ }^{H_{0}}: \operatorname{Det}|R=1|[3]$.

$$
\chi_{\text {пабі }}^{2}=\left[n-1-\frac{1}{6}(2 m+5) \lg \text { DetR }\right] \text {. }
$$

Since $\chi_{\text {набл }}^{2}=248,62>\chi_{\text {табл }}^{2}(60 ; 0,05)=79,08$, the $H_{0}$ hypothesis is rejected, which confirms the presence of multicollinearity. Due to this, it seemed appropriate to form the additional set of specific indicators, which would be composed based on the initial set, but would be more compact. In order to select the most informative factors - the indicators on the analyzed specific criteria - the principal component analysis was used, allowed reducing the dimension of the space of the initial set of indicators without significant loss of informativeness, and to eliminate multicollinearity and low "variability" (Bakumenko, \& Korotkov, 2008).

The principal component analysis substantially represents the selection of a new orthogonal coordinate system in the space of observations. If we place the axes of the initial variables orthogonally to each other, we can find that in this (multidimensional) space the objects are grouped (by their point locations, defined by the certain coordinates of the points) in the form of a cloud or concentration ellipse, which is more elongated in one directions and almost fold in others. If we draw some axes in accordance with the axes of concentration ellipse, we can talk about the selection of factors and measure the relative significance of these factors in terms of dispersion. Thus, it is usually found that the thickness of such concentration cloud at some axes is so small that these axes can be excluded from further consideration. The direction, along which the array of observations has the greatest variation, is selected as the first principal component. The choice of each subsequent principal component is conducted so that the variation of observations along it is maximum, and this principal component is othogonal to the other principal components, selected before (Dubrov, 2000).

A mathematical model of principal components is based on a logical assumption that the values of a variety of interdependent features generate some common result. In linear form ${ }^{X j}$ the equation of the dependence of the result $F$ on $X$ in the matrix form is written as follows: $F=X B$, where $B$ is the vector of the parametric values of the linear equation of constraints.

The principal component analysis is linear and additive and does not require any hypotheses about the variables. When using the principal component analysis, the $m$-initial features $x_{1}, x_{2}, \ldots x_{m}$ are orthogonally transformed to the principal components $f_{1,2,} f_{2}, \ldots f_{r}$, which are statistically independent. Thy dependence of the principal components on the values of elementary features is written using the following formula:

$$
F=A^{-1} Z^{\prime} \text {, or, } f_{r i}=a_{1 r} z_{i 1}+a_{2 r} z_{i 2}+\ldots a_{m r} z_{i m}
$$

where $z_{i j}$ - the value of the $j$-th variable (indicator) for the $i$-th object (region);

$$
f_{r i}-r \text {-th principal component } F_{r} \text { for the }{ }^{i} \text {-th objects (region); }
$$

$a_{j r}$ - weight of the $r$-th principal component for the ${ }^{j}$-th variable (the estimate of the partial correlation coefficient of the ${ }^{j}$-th feature with the $r$-th principal component).

Based on these fundamental principles, the reduction of the space of the considered features was conducted using the method of factor analysis - the principal component analysis, which is based on the notion of the complex nature of the phenomenon under study, expressed in the interrelations and interdependence of individual features. The method of principal components not only allows obtaining the information, which helps us to identify the latent variables, but also represents the way to quantify the values of these variables (Dubrov, 2000). 


\section{Analysis Results}

Analysis of the countries of the first group with very high level of human development. This group included 49 countries. However, due to the absence of certain indicators, a number of counties were excluded, and the analysis was conducted for 41 countries with the average human development index equal to 0.879 (Table 1):

Table 1 - The countries with very high human development index

\begin{tabular}{|c|c|c|c|c|c|}
\hline The country & Human Development Index & The country & Human Development Index & The country & Human Development Index \\
\hline Norway & 0,955 & Iceland & 0,906 & Greece & 0,860 \\
\hline Australia & 0,938 & Denmark & 0,901 & Cyprus & 0,848 \\
\hline United States & 0,937 & Israel & 0,900 & Malta & 0,847 \\
\hline Netherlands & 0,921 & Belgium & 0,897 & Estonia & 0,846 \\
\hline Germany & 0,920 & Austria & 0,895 & Slovakia & 0,840 \\
\hline New Zealand & 0,919 & Singapore & 0,895 & Qatar & 0,834 \\
\hline Ireland & 0,916 & France & 0,893 & Hungary & 0,831 \\
\hline Sweden & 0,916 & Finland & 0,892 & Poland & 0,821 \\
\hline Switzerland & 0,913 & Slovenia & 0,892 & Chile & 0,819 \\
\hline Japan & 0,912 & Spain & 0,885 & Lithuania & 0,818 \\
\hline Canada & 0,911 & Italy & 0,881 & United Arab Emirates & 0,818 \\
\hline Korea (Republic of) & 0,909 & Luxembourg & 0,875 & Portugal & 0,816 \\
\hline Hong Kong, China (SAR) & 0,906 & United Kingdom & 0,875 & Latvia & 0,814 \\
\hline & & Czech Republic & 0,873 & Argentina & 0,811 \\
\hline
\end{tabular}

The analysis of descriptive statistics allowed making the general conclusion for this group of countries. Conditionally, in this abstract country over $80 \%$ of the popuiation are satisfied with the freedom of choice, almost $88 \%$ are satisfied with the society, in which they live. About $43 \%$ of the population trust the government, and $67.32 \%$ feel safe. At the same time murder rate in this country is less than two people per 100 thousand. The average duration of training is almost 11 years. The GNI per capita is over 30 thousand USD. The mortality rate at birth is 11.34 per 100 thousand living. About 13 women aged 15-19 give birth to children. About a quater of the seats in parliament belongs to women. Over $80 \%$ of female and male population over 25 years old have at least secondary education. More than a half of women from 15 years old have an active economic position. The infant mortality per 1,000 births is slightly more than 4 people. On average, 3 people from 1000 are doctors. Almost all houses in the country (99.58\% of the population) are provided with electricity; $48.43 \%$ per 100 people have their own PCs and 24.95\% have the Internet access. The population of the country is slightly more than 29 million people, and 6\% more boys are born in comparison to girls. People living in this country are satisfied with living conditions for more than $66 \%$. In such a country the Human Development Index is 0.879 .

Application of the principal component analysis for identifing the generalizing characteristics of the quality of living for the countries with very high level of human development.

The decision on the number of extracted principal components was made taking into account Kaiser criterion and the "scree plot", which allows visual determining of the number of selected principal components. The essence of these methods is to keep the factors, engenvalues of which are greater than one, and to take into account the percent of accumulated dispersions of the factor variables.

Having applied this method to the first group of countries with very high level of development, we obtained the table of engenvalues of the principal components, which allowed identifying five major factors (Table 2).

Table 2 - Engenvalues of the principal components for the first group of countries

\begin{tabular}{|c|c|c|c|}
\hline No. of the factor & Engen-values & \% of explained variation & \% of accumulated explained variation \\
\hline 1 & 5,83 & 26,49 & 26,49 \\
\hline 2 & 4,55 & 20,69 & 48,19 \\
\hline 3 & 3,37 & 15,32 & 62,52 \\
\hline 4 & 2,42 & 11,00 & 73,52 \\
\hline 5 & 1,08 & 4,92 & 78,44 \\
\hline
\end{tabular}

Determining the number of factors, which is necessary for the adequate model building, was also conducted based on the scree test (Figure 1).

Based on the results of the analyisis of sufficient and necessary number of factors, conducted by various methods, 
we made a conclusion about the reliability of the selection of five factors for the adequate building of the model of factor analysis. The basic results of the factor analysis are expressed in the set of factor loads and factor weights. The factors are determined as the standardized indicators with zero mean and unit dispersion. Therefore, positive factor weights correspond to the objects, for which the degree of manifestation of properties is more than average, and negative factor weights correspond to the objects, for which the degree of manifestation of the properties is less than the average.

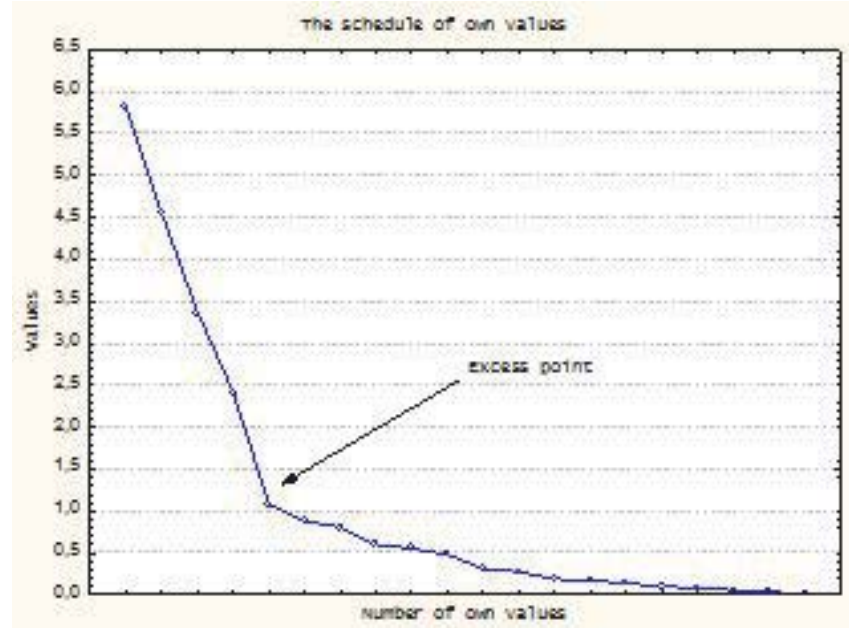

Figure 1 - The plot of engenvalues (scree plot)

The data on factor loads allowed making conclusions about the set of initial features, which reflect a particular factor, and about the relative weight of individual factor features in the structure of each factor. The value of factor weights can be regarded as the value of the index, characterizing the level of the object's development in the aspect under consideration (Table 3).

Table 3 - The matrix of factor loads for the five principal components

\begin{tabular}{|c|c|c|c|c|c|}
\hline & factor1 & factor2 & factor3 & factor4 & factor5 \\
\hline$x_{1}$ & 0.878 & 0.069 & -0.012 & 0.140 & 0.056 \\
\hline$x_{2}$ & 0.761 & 0.091 & 0.042 & 0.218 & -0.174 \\
\hline$x_{3}$ & 0.780 & -0.125 & -0.184 & -0.199 & -0.013 \\
\hline$x_{4}$ & 0.854 & 0.093 & 0.337 & -0.068 & -0.014 \\
\hline$x_{5}$ & -0.456 & 0.186 & -0.473 & -0.062 & 0.141 \\
\hline$x_{6}$ & -0.061 & 0.722 & 0.139 & 0.207 & 0.382 \\
\hline$x_{7}$ & 0.758 & -0.109 & 0.190 & -0.402 & 0.034 \\
\hline$x_{8}$ & -0.090 & -0.154 & -0.835 & 0.106 & 0.181 \\
\hline$x_{9}$ & -0.119 & -0.129 & -0.900 & -0.111 & 0.085 \\
\hline$x_{10}$ & 0.391 & 0.099 & -0.046 & 0.849 & -0.072 \\
\hline$x_{11}$ & 0.149 & 0.971 & 0.035 & -0.030 & -0.051 \\
\hline$x_{12}$ & 0.023 & 0.968 & 0.147 & 0.006 & 0.031 \\
\hline$x_{13}$ & 0.579 & 0.383 & 0.050 & 0.176 & -0.129 \\
\hline$x_{14}$ & 0.573 & -0.187 & -0.251 & -0.519 & -0.156 \\
\hline$x_{15}$ & -0.169 & -0.035 & -0.873 & -0.213 & 0.055 \\
\hline$x_{16}$ & -0.148 & -0.109 & 0.269 & 0.508 & -0.260 \\
\hline$x_{17}$ & 0.080 & 0.980 & 0.091 & 0.008 & -0.002 \\
\hline$x_{18}$ & -0.056 & 0.377 & 0.856 & 0.071 & 0.074 \\
\hline$x_{19}$ & 0.632 & 0.433 & 0.251 & 0.173 & 0.370 \\
\hline$x_{20}$ & 0.416 & 0.342 & 0.416 & 0.464 & 0.331 \\
\hline$x_{21}$ & -0.014 & 0.071 & -0.116 & -0.152 & 0.827 \\
\hline$x_{22}$ & -0.159 & -0.059 & 0.597 & 0.025 & 0.325 \\
\hline$x_{23}$ & 0.771 & 0.209 & 0.023 & 0.236 & 0.207 \\
\hline & 5.587 & 4.189 & 4.208 & 2.000 & 1.446 \\
\hline & 0.243 & 0.182 & 0.183 & 0.087 & 0.063 \\
\hline & & & &
\end{tabular}


Selection of the necessary subset of weights for each of the principal components was carried out on the basis of visual assessment of the analytical results - only weights, the absolute values of which exceeded 0.7 , were taken.

The following coefficients of information load were obtained for each components: for the first principal component $k_{1}=69.02 \%$; for the second principal component $k_{2}=80.25 \%$; for the third principal component $k_{3}=71.34 \%$; for the fourth principal component $k_{4}=36.06$; for the fifth principal component $k_{5}=47.33 \%$. Since the coefficients for the fourth and fifth components are low enough, the decision on the number of principal components was reviewed.

In the result of the recalculations with the axes rotation by the method of Varimax of initials, three principal components with factor loads were obtained (Table 4).

Table 4 - The matrix of factor loads for three principal components

\begin{tabular}{|c|c|c|c|}
\hline Varimax the initial & factor 1 & factor 2 & factor 3 \\
\hline$x_{1}$ & 0.876 & 0.117 & 0.020 \\
\hline$x_{2}$ & 0.761 & 0.094 & 0.106 \\
\hline$x_{3}$ & 0.783 & -0.139 & -0.218 \\
\hline$x_{4}$ & 0.851 & 0.084 & 0.317 \\
\hline$x_{5}$ & -0.458 & 0.201 & -0.486 \\
\hline$x_{6}$ & -0.079 & 0.811 & 0.151 \\
\hline$x_{7}$ & 0.759 & -0.151 & 0.097 \\
\hline$x_{8}$ & -0.086 & -0.077 & -0.800 \\
\hline$x_{9}$ & -0.112 & -0.109 & -0.906 \\
\hline$x_{10}$ & 0.388 & 0.222 & 0.153 \\
\hline$x_{11}$ & 0.137 & 0.916 & 0.028 \\
\hline$x_{12}$ & 0.008 & 0.935 & 0.139 \\
\hline$x_{13}$ & 0.575 & 0.374 & 0.099 \\
\hline$x_{14}$ & 0.581 & -0.285 & -0.346 \\
\hline$x_{15}$ & -0.163 & -0.044 & -0.901 \\
\hline$x_{16}$ & -0.146 & -0.091 & 0.394 \\
\hline$x_{18}$ & 0.067 & 0.940 & 0.087 \\
\hline$x_{19}$ & -0.068 & 0.375 & 0.841 \\
\hline$x_{20}$ & 0.618 & 0.536 & 0.259 \\
\hline$x_{21}$ & 0.402 & 0.479 & 0.486 \\
\hline$x_{22}$ & -0.027 & 0.237 & -0.206 \\
\hline$x_{23}$ & -0.167 & 0.010 & 0.562 \\
\hline$x_{13}$ & 0.763 & 0.299 & 0.064 \\
\hline Shersion & 5.546 & 4.470 & 4.409 \\
\hline general dispersion the general disp & 0.241 & 0.194 & 0.192 \\
\hline
\end{tabular}

Three principal components have high coefficients of informativeness: $k_{1}=69.31 \% ; k_{2}=72.84 \% ; k_{3}=67.58 \%$. The values of these coefficients give grounds to assert that the compositon of the selected components is reliable.

The first factor included the largest number of selected variables: $x_{1}$ - satisfaction with freedom of choice (\%); $x_{2}$ satisfaction with society (\%); $x_{3}$ - trust in government (\%); $x_{4}$ - sense of security (\%); $x_{7}$ - GNI per capita (\$); $x_{23}$ - overall life satisfaction (from 1 to 10). This factor can be interpreted as "Satisfaction of the population with social conditions".

The second factor was formed by the following indicators: $x_{6}$ - average duration of training (years); $x_{11}$ - people with at least secondary education, women (\% aged 25 and above); $x_{12}$ - people with at least secondary education, men (\% aged 25 and above); $x_{17}$ - people with at least secondary education (\%, aged 25 and above.). This factor characterized "Level of education".

The third factor included the following indicators with the highest correlation: $x_{8}$ - maternal mortality rate (per 100 000 live birhing mothers); $x_{9}$ - adolescent fertility rate (births per 1000 women aged $15-19 ; x_{15}$ - mortality at birth (per 1 000 live births); $x_{18}$ - electrification rate (\% of population). This factor can be regarded as "Demographic loads".

According to the following objective of the analysis - identification of the dependance of the Human Development Index $\mathrm{HDI}-\mathrm{y}$ on the selected principal factors $\mathrm{f1}, \mathrm{f2}$ and $\mathrm{f3}$, the multiple regression equation was developed. The Human Development Index was used as the dependent variable.

The regression equation for principal factors looks as follows:

$\hat{y}=0.881+0.021 f 1+0.018 f 2+0.017 f 3$ 
t-statistics (5.36) (4.42) (4.22)

$R^{2}=0.66 \quad F(3,34)=22,04 \quad S E=0,024$

The power of influence of the factors on the Human Development Index of the selected factors is determined by standardized regression coefficients $-\beta$ :

$\beta_{1}=0,54 ; \quad \beta_{2}=0,44 ; \quad \beta_{3}=0,42$

According to the data obtained all three factors in this model are significant and have a positive influence on the human development.

Thus, the greatest influence on the HDI in the countries with very high level of human development has the component "Satisfaction of the population with social conditions", the second place belongs to the component "Level of education", and the third place is taken by the component «Demographic loads».

Since the first group of the countries with very high level of human development includes quite a lot of countries $49^{3}$ (however the data are available not for all the countries, and the analysis considers the data on 41 countries), the data spread varies enough for many indicators (Table 5):

Table 5 - Descriptive statistics for variables

\begin{tabular}{|c|c|c|c|c|c|}
\hline Variables & Average & Min & Max & Scope & Standard deviation \\
\hline $\boldsymbol{y}$ & 0.88 & 0.81 & 0.96 & 0.14 & 0.04 \\
\hline$x_{1}$ & 80.26 & 52 & 95 & 43 & 13.93 \\
\hline$x_{2}$ & 87.76 & 74.24 & 94.67 & 20.43 & 5.77 \\
\hline$x_{3}$ & 42.58 & 11 & 89 & 78 & 19.03 \\
\hline$x_{4}$ & 67.32 & 39 & 89 & 50 & 12.47 \\
\hline$x_{5}$ & 1.68 & 0.3 & 6.6 & 6.3 & 1.36 \\
\hline$x_{6}$ & 10.95 & 7.28 & 13.27 & 5.99 & 1.28 \\
\hline$x_{7}$ & 30601.12 & 14724 & 87477.87 & 72753.87 & 13652.18 \\
\hline$x_{8}$ & 11.34 & 2 & 77 & 75 & 12.91 \\
\hline$x_{9}$ & 13.2 & 3.93 & 55.99 & 52.05 & 11.56 \\
\hline$x_{10}$ & 25.32 & 0.1 & 44.7 & 44.6 & 10.21 \\
\hline$x_{11}$ & 83.68 & 40.9 & 100 & 59.1 & 14.57 \\
\hline$x_{12}$ & 86 & 40.2 & 100 & 59.8 & 13.91 \\
\hline$x_{13}$ & 53.77 & 37.9 & 70.8 & 32.9 & 6.13 \\
\hline$x_{14}$ & 69.06 & 58.4 & 95.2 & 36.8 & 6.37 \\
\hline$x_{15}$ & 4.18 & 2 & 12 & 10 & 2.12 \\
\hline$x_{16}$ & 3.16 & 1.09 & 6.04 & 4.95 & 0.91 \\
\hline$x_{17}$ & 84.72 & 40.42 & 100 & 59.58 & 14.24 \\
\hline$x_{18}$ & 99.58 & 97.2 & 100 & 2.8 & 0.47 \\
\hline$x_{19}$ & 48.43 & 9.05 & 96.24 & 87.19 & 24.99 \\
\hline$x_{20}$ & 24.95 & 8.19 & 38.1 & 29.91 & 8.29 \\
\hline$x_{21}$ & 29.3 & 0.33 & 315.79 & 315.46 & 55.16 \\
\hline$x_{22}$ & 1.06 & 1.04 & 1.1 & 0.06 & 0.01 \\
\hline$x_{23}$ & 6.62 & 4.9 & 7.8 & 2.9 & 0.81 \\
\hline & & & & & \\
\hline
\end{tabular}

The greatest deviation among the countries of the first group corresponds to the indicator of the GNI per capita, $\$$, to the number of personal computers per 100 people and to the indicators, which characterize the level of education in the countries. The sufficient data spread is also observed for other indicators. For the indicators $x_{3}, x_{5}, x_{7}, x_{8}, x_{9}, x_{10}$, $x_{15}, x_{19}, x_{20}, x_{21}$ the coefficient of variation accounted for over $33 \%$ i.e. T.ethe population is heterogeneous.

In this regard, at the next stage of the study cluster analysis was conducted for this group of countries by combined principal factors - the principal components, obtained at the previous stage of the study.

In order to carry out the classification, the cluster analysis was used. The Euclidean distance was used as the measure of the distance between points:

${ }^{3}$ According to the data of the United Nations Development Programme: Human Development Index 2014. 


$$
d_{E}\left(x_{i}, x_{j}\right)=\sqrt{\sum_{l=1}^{k}\left(x_{i l}-x_{j l}\right)^{2}},
$$

where $x_{i l}, x_{j l}$ - the value of the $l$-th component of the $i_{\text {-th }}(j$-th) object $(l=1,2, \ldots, k, i, j=1,2, \ldots, n)$.

When clustering using various procedures, the best partition was shown by the Ward method. In most cases the classification algorithms and the quality criteria are linked, i.e. certain algorithms provide obtaining the extreme value of a corresponding quality functional. The Ward method differs from all other methods since it uses the methods of dispersion analysis to measure the distances between clusters. In this method the target function is the intragroup sum of squared deviations, which is the sum of the squares of the distances between each point (objects) and the average of the cluster, containing this object. At each step such two clusters are combined, which result in the minimal increase in the target function, i.e. the intragroup sum of squares. This method aims to combine closely located clusters (Soshnikova, 1999). The result of using the method is a dendrogram (Figure 2) with deeply exaggeratedly separated clusters.

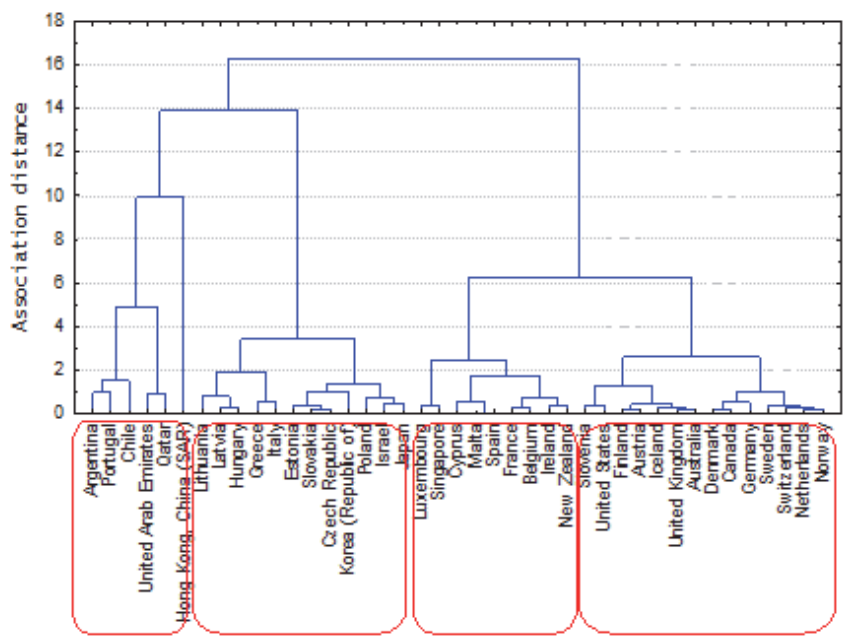

Figure 2 - Dendrogram of cluster analysis for the first group of countries with very high level of human development

As a result of hierarchical procedures for combining, four groups of countries - for clusters - were separated. The first group - the first cluster - included 14 countries: Canada, United Kingdom, United States, Australia, Slovenia, Iceland, Germany, Finland, Australia, Sweden, Denmark, Switzerland, Netherlands, Norway.

The second group - the second cluster - included the following countries: Cyprus, Spain, France, Belgium, Singapore, Luxembourg, Ireland, New Zealand, Malta.

The third group - cluster comprised of the following countries: Latvia, Lithuania, Hungary, Greece, Italy, Estonia, Slovakia, Czech Republic, Poland, Israel, Japan, Korea (Republic of Korea).

The fourth group - cluster was formed of the following countries: Argentina, Chile, Portugal, Qatar, United Arab Emirates, Hong Kong, China (SAR).

\section{Discussion}

The obtained results of the partition of the classification of countries, belonging to the group with very high level of human development, proved that the countries of this group are heterogeneous in terms of the system of indicators, which characterize their quality of life. The Human Development Index by the groups of countries (clusters) totaled: in the first cluster -0.912 , in the second cluster -0.886 , in the third cluster -0.859 and in the fourth cluster -0.834 . In terms of all considered indicators, the best conditions for human development are provided in the countries of the first cluster (on average, 348 million people live in the countries belonging to the first cluster). The second place is taken by the countries of the second cluster (on average, 265 million people live in the countries of this cluster). The countries of the thrid cluster are significantly different in many aspects. Trust in government in these countries is almost two times lower than in the countries of the other groups: (1cl.-47.214; 2cl.-51.556; 3cl.-26.917; 4cl.-55.4), the lowest GNI per capita, \$: (1cl.35674.281; 2cl.-32065.416; 3cl.-21523.255; 4cl.-37672.147), the highest murder rate per 100.000 people: (1cl.-1.207; 
2cl.-1.244; 3cl.-2.333; 4cl.-1.617). The average population in the countries of the third cluster is 27.190 million people. The countries of the fourth cluster with the Human Dvelopment Index equal to 0.834 are mainly distinguished by high maternal mortality rate (deaths per 100,000 live births): (1cl.-8.714; 2cl.-9.333; 3cl.-9.667; 4cl.-25.8), high adolescent fertility rate (births per 1,000 women aged 15-19): (1cl.-10.724; 2cl.-9.746; 3cl.-11.438; 4cl.-27.633), high mortality at birth (deaths per 1,000 live births): (1cl.-3.514; 2cl.-3.444; 3cl.-4.417; 4cl.-7.2), the lowest level of education, availability of personal computers and the Internet access (per 100 people). The average population of the countries of the fourth group is 14.414 million people.

\section{Conclusion}

In this work, the approach to the assessment of the quality of life from the point of classification of all countries of the world by the indicators of human development is suggested. We considered the first group of countries, classified by the UN as the countries with very high level of development. This group included 49 countries, and the analysis was carried out for 41 countries. The analysis showed that the countries of this group are heterogeneous, and their analysis requires a complex of indicators and tools based both on objective statistical data and on subjective indicators, which take into account the opinion of the people about the quality of life and the perception of the surrounding environment.

\section{Acknowledgements}

This article was prepared under a grant of the Russian Humanitarian Science Foundation (project "Demoekonomichesky potential of the region: macrosystemic approach" \# 15-02-00567).

\section{References}

Bakumenko, L.P. (2012). A Methodology of Statistical Research of the Quality of Life in a Region. Moscow State University of Economics, Statistics and Informatics (MESI), Moscow, P.54.Life

Bakumenko, L.P. (2011). Statistical Aspects of the Research of the Population Life Quality. Yoshkar-Ola, MarSTU. 10 p.p.

Ayvazyan, S. (2001). Applied Statistics. Basics of Econometrics: textbook for high school in 2 vol. 2nd ed. Moscow UNITY-DANA. 2001. $-432 \mathrm{p}$.

Bakumenko, L., Korotkov, P. (2008). Selection of the Most Informative Indicators by the Method of Principal Components. Moscow, MESI, $95 \mathrm{p}$.

Dubrov, A. (2000). Multidimensional Statistical Methods: textbook. Moscow, Statistica, 352 p.

Fyodorov, Y. (2008). Report on Human Development in the Russian Federation. Moscow, Human Rights, 140 p.: tables, figures, maps. Ishikawa, K. (1998). Japanese Methods of Quality Management. Mosscow, Economics, 246 p.

Soshnikova, L. (1999). Multidimensional Statistical Analysis in Economics. Moscow, UNITY, 598 p.

Forrester, D. (2003). World Dynamics: translation from English. Moscow, AST; SPb.: TerraFantastica, 2003. 379 p.

Kolesov, V. \& McKinley, T. (2000). Human Development: A New Dimension of Social and Economic Progress: study guide.T. McKinley (UNDP, New York). - Moscow. Human Rights, 569 p.

Deming, E. (1986). Out of the Crisis. Cambridge University Press.

Human Development Report 2010: human development report. [Electronic resource]: http://www.un.org/ru/development/hdr/2010/c hdr_2010_pr2.pdf

The Better Life Index - information about the research [Electronic resource] // The Centre of Humanitarian Technologies. - URL: http://gtmarket.ru/integrated-research/oecd-better-life-index/info

Human Development Report 2014 [Electronic resource]: Human Development Reports. Electronic data of the United Nations Development Programme (UNDP), 2014. - URL: http:// www.hdr.undp.org/

Human Development Report 2013 [Electronic resource]: Human Development Reports. Electronic data of the United Nations Development Programme (UNDP), 2013. - URL: http://hdr.undp.org/en/reports/global/hdr2013/ (data: 25.07.2013). 
